\section{Publications from the Humboldt Kolleg Ecuador 2019 \\ "Breaking Paradigms: Towards a Multi-, Inter- and \\ Transdisciplinary Science" \\ In commemoration of the 250th Anniversary of February 21th - 24th, 2019. \\ Ibarra, Ecuador}

\section{Alexander von Humboldt \\ Stiftung / Foundation}

\section{Humboldt Kolleg}

Ecuador 2019

February 22th - 24th, 2019 Ibarra, Ecuador

\section{Bionatura Conference Series Vol 2. No 1. 2019}

"Breaking Paradigms: Towards a Multi-, Inter- and Transdisciplinary Science" In commemoration of the 250th Anniversary of Alexander von Humboldt
REVISION/REVIEW

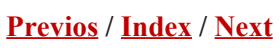

\title{
Prostate Cancer: Treatments and Diagnosis
}

\author{
Robert Angulo ${ }^{1}$, Bryan Herrera ${ }^{1}$, and Keila Ibarra ${ }^{1}$ \\ available in: http://dx.doi.org/10.21931/RB/CS/2019.02.01.27
}

\begin{abstract}
Prostate cancer is a disease in which malignant (cancer) cells form in the tissues of the prostate. Prostate tumors were responsible for nearly six thousand deaths in Spain in 2016 as the symptoms are very silent and appear like advanced cancer or when this cancer has proliferated to other organs and senses. Therefore, there are 4 characteristic stages of this type of cancer that are classified according to their extension in the body. To make the diagnosis of this type of disease there are methods that in many cases show to be effective and in others not depending on the stage in which you are. Therefore, the number of treatments against prostate cancer has been increasing over the years from medications that help prevent tumor proliferation to strong surgeries. These treatments are not a solution to fight cancer, they simply have the function of maintaining cancer and its proliferation in order to generate a suitable lifestyle for patients for a time. Currently, several investigations have focused on combating prostate cancer through clinical trials that promise to generate favorable and acceptable solutions for patients.
\end{abstract}

Keywords: Prostate, Cancer, Metastases, Treatments, Diagnosis

\section{INTRODUCTION}

Prostate cancer is defined as a multi-stage process that requires repeated cycles of somatic mutation, which is generated in the prostate gland, a small walnut-like structure that is part of the male reproductive system ${ }^{1}$. There are four stages of prostate cancer that are related and classified with respect to the local extent of the tumor, as well as 
the rapid proliferation of cancer cells present in the prostate gland. The symptoms of prostate cancer are quite silent and appear as cancer progresses or when cancer has proliferated to other organs or tissues ${ }^{2}$. Treatments against prostate cancer have great diversity because they are divided in relation to the size and characteristics of the tumor, but also with age and pathologies associated with the patient. Screening tests are the search for cancer before the person has any symptoms. This can help to find cancer at an early stage, that is, the abnormal tissue or the cancer are in their initial stages, thus stimulating some facility to treat them ${ }^{2,3}$. When the symptoms appear, cancer could begin to spread and consequently the difficulty and level of the treatment increases significantly ${ }^{3}$.

The prostate is a gland belonging to the genitourinary system of the man that is located in front of the rectum and under the exit of the bladder. The function of the prostate is related to reproduction ${ }^{1}$. This serves as a valve which closes or opens the passage of urine while intercourse occurs, also secret substances during the act which serve not only as a lubricant but clean the urinary tract of urine and bacteria remain for the next step of semen and thus avoid its contamination ${ }^{3}$.

It is considered the second most common type of cancer in men, usually many do not have symptoms so they are not subjected to therapy. Several epidemiological studies of prostate cancer have shown that various factors such as lifestyle have contributed to its development ${ }^{4,5}$. Obesity, height, physical activity, smoking, products made of tomato, coffee, fish have positive as well as negative effects on the development of prostate cancer. Prostate cancer according to age occurs more frequently over 40 years, studies have shown that black people and men of African descent are more likely to have prostate cancer while in Americans and Asians is less ${ }^{6}$. People who eat red meat, dairy, high-fat foods also support development. Prostate inflammation shows an increased risk of cancer or may show that the tissue contains cancer, people who have had vasectomy have also increased the risk of developing it. Because so many factors can develop prostate cancer, early detection with the use of PSA detection is important ${ }^{1,3}$.

\section{DIAGNOSIS}

\section{Detection}

At the moment of presenting symptoms of prostate cancer and going to the doctor, exams will be performed depending on how the patient responds to the questions that the doctor makes, in order to proceed to the respective checkup. Among the most frequent questions, we find if there are urinary problems or in sexual encounters, what has been the period that has suffered such discomfort and if there is a pain in the bones because prostate cancer can get to spread to the bones.

\section{PSA}

The analysis of PSA is based on the measurement of this protein produced by the cells of the prostatic gland that can be normal or malignant. A sample is obtained that is analyzed in ( $\mathrm{ng} / \mathrm{ml})$ knowing that the high concentration can be due to a prostate cancer ${ }^{7}$. However, high levels may be due to some benign condition such as inflammation and benign hyperplasia. The observations are based on the speed at which the PSA increases and depending on the level a biopsy is performed. A person of 40 years must have a range of PSA between 0 to $2.5 \mathrm{ng} / \mathrm{ml}$, a man of 50 years 0 to 4 $\mathrm{ng} / \mathrm{ml}^{4,8}$. However, it is important to take into account the size of the prostate because a large prostate may have a large PSA level, medications that alter the PSA value, sexual stimulation, etc. ${ }^{7,9}$.

\section{Transrectal ultrasound}

Transrectal ultrasound or transrectal ultrasound is a test used to detect conditions in the prostate, to determine if there is an abnormal growth in the prostate after diagnosing symptoms such as urinary problems, abnormal results in the 
The test consists of introducing a small probe of the width of a lubricated finger in the rectum, this emits sound waves inside the prostate and in response, there are echoes which are studied by the computer, establishing a pattern to obtain an image (Figure 1) ${ }^{9,11}$. The importance of this test is that it detects if there are cancerous tumors in the prostate in patients who may have a normal PSA measurement and in a biopsy is used as a guide to using the biopsy needles in the correct area of the prostate ${ }^{3,12}$.

It is a method not very expensive and accessible to the patient, the images do not produce any type of radiation, and the image can arrive to emit very precise and clear results that the x-ray images do not visualize as "soft tissues" and in contrast to the biopsy is not painful, and there are no high risks so repeating it does not create any problems in the future ${ }^{8}$.

\section{Prostate biopsy}

It is a test that presents a certain percentage of risk, but very precious in detecting the type of cancer, in this process a sample of the prostate will be taken ${ }^{13}$. As the first point an ultrasound is performed, which will be used as a guide to insert a biopsy needle which is thin and hollow, a small portion of the prostate tissue is taken from the exact area (Figure 2), it is repeated regularly between 8 and 18 times, but usually 12 samples from different parts of the prostate, but all guided by the image obtained from the rectal ultrasound examination ${ }^{10}$.

Each sample taken very quickly can cause pain or discomfort, but first, the area from which the sample will be drawn is numbed. To reduce risks of infection among others it is recommended to administer antibiotics before and afterwards ${ }^{10,13}$. The patient will feel pain and irritation in the areas taken during the days, so it is normal that there are slight blood samples both in the rectum and in the urine. and in the semen. There are many flaws in the biopsy because cancer can be in a too small area of the prostate, so if you take it incorrectly the sample will get negative data producing great doubts about whether there is possible prostate cancer, that is why It is necessary to repeat the biopsy ${ }^{3,13}$.

\section{TREATMENTS}

\section{RADIATION THERAPY}

This treatment is divided into two types of radiation that are:

\section{External beam radiation therapy (EBRT)}

The radiation beams are focused on the prostate gland from a machine that is outside the body. This radiation is used to cure earlier stage prostate cancers or relieve symptoms such as bone pain if cancer has spread to different areas of the body.

To begin with this treatment, it is necessary to take specific and careful measurements to know the correct angles to point the radiation beams and the proper dose of radiation. This procedure is called simulation. The radiation of this treatment is similar to an x-ray, however, it is stronger and painless. Newer external beam radiation therapy procedures are focused on radiation more precise allowing to emit higher doses of radiation to the tumor while reducing the exposure time of nearby healthy tissues ${ }^{14}$. 
This treatment is also called seed implantation or interstitial radiation therapy whose goal is the use of small radioactive pellets (seeds) that will be placed directly into the prostate.

Brachytherapy is used in patients with early stage prostate cancer that have slow growth. When this therapy is combined with external radiation is a good option for patients who have a higher risk of cancer growing outside the prostate. However, brachytherapy is not able to work as well in patients with large prostate glands because it is not possible to place the seeds in all the correct locations ${ }^{14}$.

\section{CRYOTHERAPY}

Cryotherapy is used to treat early-stage prostate cancer and it is a great option if cancer come back after the radiation therapy. However, it is not recommendable to use cryotherapy as the first treatment for prostate cancer. Similar to brachytherapy, it is not a good option for patients with large prostate glands ${ }^{14}$.

The treatment consists of a transrectal ultrasound (TRUS) to guide several needles through the skin between the anus and scrotum to the prostate. Then, very cold gases pass through the needles to freeze and destroy the prostate without damage the nearby tissues. Also, warm saltwater circulates through a catheter in the urethra during the process ${ }^{14}$.

Cryotherapy is less invasive than surgery, so it is painless and produces less blood loss. However, this treatment is not better than radiation for more advanced prostate tumors.

\section{HORMONE THERAPY}

Hormone therapy is also called androgen deprivation therapy (ADT) or androgen suppression therapy. The goal of this kind of treatment is to reduce levels of male hormones called androgens to stop them from affecting prostate cancer cells ${ }^{14}$.

Androgens are responsible for stimulating prostate cancer cells to grow. The main androgens in the body are testosterone and dihydrotestosterone (DHT). Most of these androgens are made by the testicles and a small amount by the adrenal glands. Reduce androgen levels or stop them to enter into prostate cancer cells often makes prostate cancers shrink or grow more slowly for a time. However, hormone therapy alone is not able to cure prostate cancer ${ }^{14}$. For this reason, it is necessary to apply other therapies such as surgery and radiation.

There are some types of hormone therapy such as:

Orchiectomy or surgical castration: In this surgery, the surgeon removes the testicles, where most of the androgens are made. This causes the most prostate cancers to stop growing. Additionally, it is the least expensive and simplest form of hormone therapy ${ }^{14}$.

LHRH agonists: Luteinizing hormone-releasing hormone (LHRH) agonists are drugs that reduce the amount of testosterone made by the testicles. The treatment with these drugs is called chemical castration or medical castration $^{14}$.

LHRH antagonist: Degarelix (Firmagon) is an LHRH antagonist. It works similar to LHRH agonists but it reduces testosterone levels more quickly. Treatment with this drug is focused on advanced prostate cancer and can be considered a form of medical castration ${ }^{14}$.

\section{CHEMOTHERAPY}


Chemo is used if prostate cancer has spread outside the prostate gland and hormone therapy is not working. Recent research has shown that chemo in combination with hormone therapy might be more helpful. Chemo is not a treatment for early stages of prostate cancer but some studies have shown that it could be helpful for a short period of time after surgery ${ }^{14}$.

In addition, chemo drugs are used one at a time and these can be: Docetaxel (Taxotere), cabazitaxel (Jevtana), mitoxantrone (Novantrone) and estramustine (Emcyt). In most cases to treat prostate cancer, the first chemo drug is docetaxel combined with steroids. If this drug does not work, the second used for the treatment is cabazitaxel ${ }^{15,16}$.

These two actual drugs have been shown to help patients to live longer than older chemo drugs because they can reduce cancer's growth and the symptoms, resulting in a better quality of life ${ }^{17}$.

\section{VACCINE TREATMENT}

The main cancer vaccine is Sipuleucel-T (Provenge). Unlike traditional vaccines, which increase the action of the immune system to help the body to prevent infections, this vaccine increases the immune system to help it attack the tumor and prostate cancer cells. Also, this vaccine is used to treat advanced prostate cancer that is not able to respond to hormone therapy 15,16 .

The procedure begins when the white blood cells are removed from the blood while being hooked up to a special machine. Then, the cells are exposed to a protein belonging to prostate cancer cells called prostatic acid phosphatase (PAP). After that, the cells are given back to the patient by infusion into a vein and the cells help to immune system cells attack the prostate cancer ${ }^{15}$.

However, some studies have shown that the vaccine is not able to stop prostate cancer from growing but it seems to help patients live several months longer. Like all other treatments, this type of treatment is not able to cure prostate cancer $^{14}$.

\section{Clinical Trials}

The study of human clinical trials in prostate cancer is very broad. According to the Clinicaltrials.gov, there are around 4341 studies, in which 1891 have completed all their stages, but only 423 of them have obtained results in humans ${ }^{21}$. In this paper, three of those studies will be mentioned and analyzed for treatment and diagnosis of prostate cancer.

\section{Vitamin D Supplementation.}

This study started its clinical trials in 2009 and since that date, many scientists have published more and more advances in this area. The purpose the researchers have used to continue developing this treatment is because vitamin $\mathrm{D}$ can help the cancer cells of the prostate to differentiate until a certain point, in which they can die. Thus, the use of Vitamin D3 can be observed as a chemopreventive agent ${ }^{19}$.

In the human clinical trials, eighty-three veterans with low-risk Prostate cancer were enrolled to participate. They were informed that they will be under active surveillance; this is that scientists were able to have control of the localization of cancer ${ }^{19}$.

There were two objectives that must be accomplished in this study. First, the patients must have results of decreasing levels of PSA in a relevant number of participants; second, scientists must know if the treatment can stabilize or 
improve the current pathology. The results of this trial concluded that there was a change in PSA (ng/mL) and in numbers of positive biopsy cores per subject during the active surveillance ${ }^{19}$.

\section{Disulfiram.}

In this clinical trial, scientist has discovered a potential inhibitor for PSA growth in vitro that will be tested in humans as a possible solution for prostate cancer. The drug used is called Disulfiram, which is a DNA methyltransferase inhibitor, and it may help restore tumor suppressor genes ${ }^{18}$.

A number of nineteen patients with recurrent prostate cancer participated in this study. The characteristic of recurrent prostate cancer in these patients showed that they have a rising PSA. The drug was administered in two cohorts. In the first one, a dose of $250 \mathrm{mg}$ was given orally for 18 days. In the second one, they duplicated the dose for the same period of time ${ }^{18}$.

The objectives of this study were to know the proportion of subjects with a demethylation response for each dose and check the clinical response after six months of the therapy. The results obtained were that the demethylation response was reduced to more than ten percent from the baseline, for both doses. Besides, there was an increase in PSA after the treatment, more than half of PSA normal levels ${ }^{20}$.

\section{F-DCFBC PSMA-based PET Imaging.}

This trial started in 2013 in the Cancer Center at John Hopkins University. Researchers were able to test the reaction of a drug called 18F-DCFBC to help find cancer that had spread from the prostate (metastases) ${ }^{20}$.

For this research, twenty patients with castration-resistant prostate cancer and hormone-naive prostate cancer were enrolled. These participants had an age above eighteen years old. The selection process was carried out with all the precaution with sixteen criteria point, in which the histological confirmation and the levels of PSA were one of them ${ }^{20}$.

The objectives of this research were to evaluate 18FDCFBC PET imaging in order to detect metastases in prostate cancer. The results concluded that the measurement of sensitivity, based on lesion by lesion analysis, defined a true positive when the lesion was a follow-up. Whereas, a progression of metastases was when the lesion was equivocal, in other words, considered negative. Thus, sensitivity is an estimation of responsive lesions to the total number of injuries analyzed ${ }^{20}$.

Following these details of each drug and therapy for prostate cancer, a table is shown to compare the different methods used to treat and diagnose this type of cancer in men (Table 1). It is clear that there is two methods for the treatment of cancer and one for diagnosis. The treatment that has a better effect on the patient is Vitamin D Supplementation. Moreover, the diagnosis therapy, 18F-DCFBC, is considered very important for the detection of metastases in the patients; it is very sensitive and it outranges the actual method since it does not affect the unconformity of the patient. 


\begin{tabular}{|c|c|c|c|}
\hline Drug /Therapy & $\begin{array}{l}\text { Vitamin-D } \\
\text { Supplementation }\end{array}$ & Disulfiram & 18F-DCFBC \\
\hline $\begin{array}{l}\text { Type of } \\
\text { intervention }\end{array}$ & Treatment & Treatment & Diagnosis \\
\hline $\begin{array}{l}\text { Positive/Negative } \\
\text { results }\end{array}$ & ++ & +- & ++ \\
\hline Details & $\begin{array}{l}\text { - It had a bigger } \\
\text { number of } \\
\text { participants; } \\
\text { however, they were } \\
\text { all veterans. There is } \\
\text { no guarantee it will } \\
\text { act the same on the } \\
\text { other part of the } \\
\text { population. } \\
\text { It reduced } \\
\text { significantly the } \\
\text { levels of PSA, until } \\
\text { the possible death of } \\
\text { cancer cells. } \\
\text { It is an easy } \\
\text { treatment that does } \\
\text { not require much } \\
\text { medical help on } \\
\text { therapy, } \\
\text { hospitalization, } \\
\text { surgery, etc. }\end{array}$ & $\begin{array}{l}\text { - It had a smaller } \\
\text { number of } \\
\text { participants, } \\
\text { making it a more } \\
\text { imprecise. } \\
\text { - The results while } \\
\text { applying the dose } \\
\text { were very } \\
\text { promising; but, as } \\
\text { the treatment } \\
\text { stopped, the } \\
\text { consequences were } \\
\text { even worse than } \\
\text { the initial } \\
\text { conditions. } \\
\text { - It is not a very } \\
\text { viable method } \\
\text { since the treatment } \\
\text { will be longer and } \\
\text { more expensive for } \\
\text { the patient. }\end{array}$ & $\begin{array}{l}\text { - It had a big } \\
\text { number of } \\
\text { participants but not } \\
\text { as many as the first } \\
\text { one. } \\
\text { - The results were } \\
\text { positive since they } \\
\text { can diagnose the } \\
\text { development of } \\
\text { metastases in the } \\
\text { early stages due to } \\
\text { its sensitivity. } \\
\text { - It is a better } \\
\text { method for } \\
\text { diagnosis since it } \\
\text { does not make the } \\
\text { patient } \\
\text { uncomfortable. }\end{array}$ \\
\hline
\end{tabular}

Table 1. Comparison of the three clinical trials for prostate cancer.

\section{CONCLUSIONS}

To conclude, we were able to analyze in this paper the treatments and diagnostic tests that are being used for prostate cancer; moreover, we suggested three methods that being applied to clinical trials, in order to improve in efficacy, precision, patient's safety, and personal well-being.

Today, even though the methods for diagnosis (transrectal ultrasound and prostate biopsy) are precise and secure, many patients do not feel comfortable, since it may cause them pain or disturbance. However, thanks to the advancement of science, many clinical trials are being accomplished for the improvement of the current therapies. Here, we have mentioned that Vitamin D3 Supplementation might be, so far, the best treatment for cancer, as well as, the implementation of 18F-DCFBC PSMA-based PET Imaging for its detection. Nevertheless, it is relevant to mention that there is still further investigation needed in order to have these studies applied to hospitals.

\section{REFERENCES}

1. Bashir MN. Epidemiology of prostate cancer. Asian Pacific J Cancer Prev. 2015;16(13):5137-41.

2. Iversen P, Røder MA, Klemann N. The drama of prostate cancer diagnostics - Authors' reply. Lancet Oncol. 2017 Mar 2;18(3): e133.

3. Klemann N, Røder MA, Helgstrand JT, Brasso K, Toft BG, Vainer B, et al. Risk of prostate cancer diagnosis and mortality in men with a benign initial transrectal ultrasound-guided biopsy set: a population-based study. Lancet Oncol. 2017 Feb 1;18(2):221-9.

4. Catalona WJ. Prostate Cancer Screening. Medical Clinics of North America. 2018.

5. Stewart RW, Lizama S, Peairs K, Sateia HF, Choi Y. Screening for prostate cancer. Seminars in Oncology.

2017.

6. Rebbeck TR. Prostate Cancer Genetics: Variation by Race, Ethnicity, and Geography. Seminars in Radiation Oncology. 2017.

7. Prensner JR, Rubin MA, Wei JT, Chinnaiyan AM. Beyond PSA: The next generation of prostate cancer 
biomarkers. Vol. 4, Science Translational Medicine. 2012.

8. Siddiqui MM, Rais-Bahrami S, Turkbey B, George AK, Rothwax J, Shakir N, et al. Comparison of

MR/ultrasound fusion-guided biopsy with ultrasound-guided biopsy for the diagnosis of prostate cancer. JAMA - J

Am Med Assoc. 2015;

9. Ghai S, Van der Kwast T. Suspicious findings on micro-ultrasound imaging and early detection of prostate cancer. Urol Case Reports. 2018 Jan 1; 16:98-100.

10. Singh PB, Moore CM, Emberton M. Prostate biopsy. In: Prostate Cancer: A Comprehensive Perspective. 2013.

11. Brown LC, Ahmed HU, Faria R, Bosaily AES, Gabe R, Kaplan RS, et al. Multiparametric MRI to improve detection of prostate cancer compared with transrectal ultrasound-guided prostate biopsy alone: The PROMIS study. Health Technol Assess (Rockv). 2018;

12. Sonn GA, Natarajan S, Margolis DJA, MacAiran M, Lieu P, Huang J, et al. Targeted biopsy in the detection of prostate cancer using an office based magnetic resonance ultrasound fusion device. J Urol. 2013;

13. Loeb S, Vellekoop A, Ahmed HU, Catto J, Emberton M, Nam R, et al. Systematic review of complications of prostate biopsy. European Urology. 2013.

14. Rosen R, Rosen G. Treating Prostate Cancer. American Cancer Society. 2019.

15. Nevedomskaya E, Baumgart S, Haendler B. Recent Advances in Prostate Cancer Treatment and Drug Discovery. International Journal of Molecular Science. 2018.

16. Asadi F, Lazennec G, Jorgensen C. Importance of Stromal Stem Cells in Prostate Carcinogenesis Process. Cancer Stem Cells Theories and Practice. 2014.

17. Denmeade S, Isaacs J. A history of prostate cancer treatment. Nature Reviews. 2002.

18. Carducci, M. A. Clinical Trials. 17 de May de 2019. Obtenido de https://clinicaltrials.gov/ct2/show/NCT01118741?recrs=e\&rslt=With\&cond=prostate+cancer\&draw $=4 \&$ rank $=24$

19. Gattoni-Celli, S. Clinical Trials. 17 de May de 2019. Obtenido de https:/clinicaltrials.gov/ct2/show/NCT00953225?recrs=e\&rslt=With\&cond=prostate + cancer\&draw=3\&rank=14

20. Szabo, Z. Clinical Trials. 17 de May de 2019. Obtenido de https://clinicaltrials.gov/ct2/show/NCT01815515? recrs $=$ e \&rslt $=$ With\&cond $=$ prostate + cancer $\&$ draw $=14 \&$ rank $=7$

21. Trials, C. Clinical Trials. 17 de May de 2019. Obtenido de https://clinicaltrials.gov/ct2/results? cond $=$ prostate + cancer\&recrs $=$ e\&age_v $=\&$ gndr $=\&$ type $=\&$ rslt $=$ With $\&$ Search $=$ Apply

22. Samadi, D. (2015). What is a Transrectal Ultrasound (TRUS)?. [image] Available at: https://prostatecancer911.com/what-is-a-transrectal-ultrasound-trus/ [Accessed 20 May 2019].

23. Mayo Clinic Staff (2019). Prostate biopsy. [image] Available at: https://www.mayoclinic.org/testsprocedures/prostate-biopsy/about/pac-20384734 [Accessed 20 May 2019].

Received: 2 April 2019

Accepted: 22 May 2019

Robert Angulo ${ }^{1}$, Bryan Herrera ${ }^{1}$, and Keila Ibarra ${ }^{1}$

Genetic Engineering, School of Biological Sciences and Engineering,

YachayTech, Urcuquí. Ecuador.

Corresponding author: keila.ibarra@yachaytech.edu.ec 